This is an Accepted Manuscript of an article published by Taylor \& Francis in European Journal of Physiotherapy on 23/04/19, available online:

https://www.tandfonline.com/doi/full/10.1080/21679169.2019.1598487 


\title{
The Effects of Mindfulness Training on Persistent or Intermittent Sub-acute Pain: Using the Headspace ${ }^{\circledR}$ Application.
}

\begin{abstract}
Background Physiotherapists have recognized the benefits of incorporating psychological interventions in their treatments. This study sought to determine the usefulness of the Headspace ${ }^{\circledR}$ Application that provides mindfulness training via a smartphone on pain.

Methods A quasi-experimental design was used and volunteers from a large metropolitan university who were coping with pain were encouraged to use the application for 6-weeks. Pain (severity and interference), selfreported mindfulness, usage of the application and participants perspectives of the application were examined. Results There was a significant reduction in pain severity $(p=0.01, r=0.70)$ and pain interference $(p=0.00, r=$ 0.81) pre-post intervention. However there was no significant change in self-reported mindfulness pre-post intervention ( $p=0.67, r=0.09$ ). The usage of the application during the intervention period varied significantly (10-674 minutes) and was not significantly correlated with pain severity (two tailed)- pre ( $\mathrm{p}=0.65, \mathrm{r}=0.10)$, post $(p=0.43 r=0.17)$ or pain interference (two tailed) pre $(p=0.75 r=0.07)$, post $(p=0.32 r=0.20)$. The participants reported positive perceptions of the application, such as it being useful in reducing pain and its convenience.
\end{abstract}

Conclusion This study provides preliminary evidence to suggest that the Headspace ${ }^{\circledR}$ application is beneficial in reducing Persistent or Intermittent sub-acute pain and the application could be a useful adjunct to physiotherapy interventions.

Key words Physiotherapy, psychological interventions, pain, Smartphone Application 


\section{Background}

Patients with persistent or sub-acute pain present a problem for all clinicians from whom they seek help as it defies a biomedical model [1] and increasingly physiotherapists have recognized the potential benefits of incorporating psychological interventions in their treatments but have felt insufficiently trained to optimize the use of such interventions [2]. Semmons [3] on the other hand reported that although physiotherapists may not have specific training in these psychological therapies they frequently incorporate concepts of these strategies into their treatment. One such psychological intervention is mindfulness and this is increasingly being used in health care to assist patients in managing pain, stress and anxiety and in targeting additional health, wellness and quality of life outcomes [4,5]. Numerous systematic reviews and randomised control trials have highlighted that Mindfulness Based Interventions (MBIs) can attenuate the experience of pain [4,5,6,7,8] Hardison and Roll [4] in their review of the literature on the use of mindfulness in physical rehabilitation concluded that mindfulness interventions are helpful for patients with musculo-skeletal and chronic pain disorders. However they state that mindfulness interventions are generally complex and not fully integrated into standard rehabilitation interventions. One way to address this dilemma is the practice of Mindfulness using an APP as it does not require extensive training for the therapist or for the patient. Furthermore, the Headspace ${ }^{\circledR}$ application has been shown to improve an individual's wellbeing [9]. Björnsdóttir et al. [6] addressed the effectiveness in terms of pain intensity and health related quality of life (HRQL) of two interventions, a traditional pain management programme and mindfulness-based cognitive therapy. The results indicated that both interventions resulted in significant changes in pain intensity although importantly the mindfulness group reported a significant improvement in their sleep and the resulting benefits of this with regard to pain [10, 11].

Mindfulness began as an Eastern meditation practice, however, there has been a recent surge in the interest in mindfulness training as a whole, in both popular culture and clinical research in Western countries, leading to an increase in mindfulness-based therapies [12,13]. In research, mindfulness is frequently defined as "paying attention on purpose, in the present moment, and non-judgmentally to the unfolding of experience moment by moment” [14, p145]. As mindfulness has evolved in recent years, differing perspectives of mindfulness have also developed, leaving debate over the definition [15]. There are a vast number of techniques and programs which are included under the term 'mindfulness'. These include 7-minute sessions on the lower end of the 
spectrum, up to hour long sessions or even 8-week long courses at the upper end, which are provided with or without face-to-face therapist guidance $[15,16,17,7]$. However there is limited research into the dose-effect response for mindfulness interventions, and as a result the recommended advice on frequency and duration per session varies $[18,19]$. Mindfulness is believed to help one connect to the way one is feeling and accept and overcome negative states without directly affecting the target of stress [20,21].

The effect of mindfulness-based interventions has been explored across a wide spectrum of pain types and they have been shown to modulate a variety of forms of pain, including both acute pain and chronic pain [20]. It has been reported that the outcomes, such as those found in the aforementioned studies, are the result of changes mediated by the brain [21,22]. Neuroimaging has been used to understand whether brain mechanisms are associated to the modulation of pain seen from mindfulness practice [23]. Results have shown that mindfulness practice improves cognitive control and emotional regulation. Zeidan et al. [24] concluded that this was achieved though the involvement of the cingulate cortices and the prefrontal cortex, resulting in adaptations in sensory representations of pain. Additionally, further research has shown that brain activation associated with pain reduction, achieved from mindfulness practice is dissociable from placebo effects [24]. However, research behind the underlying neurobiological mechanisms which may produce this analgesic effect is still in its infancy [19].

However, a number of limitations exist in the current mindfulness literature. Studies completed on mindfulness interventions, including the aforementioned studies which explored the effects of mindfulness on pain, commonly have small sample sizes and a lack of an active control group [19]. However, studies have also failed to accurately detail adherence and the skill acquisition of participants $[25,26]$. In some studies, mainly selfreported outcome measures in a scale format were used and therefore participant reactions and views towards the intervention were not considered [12].This indicates the need for more research in the field, tackling these issues in order to produce research which can inform clinical practice. Majeed [8] state that limitations include a possible increase in pain resulting from an increased attention to their body sensations and the various different ways of delivering the interventions make it difficult to standardise the research . Limited data is available about the durability of treatment and Cherkin et al [27] found that treatment gains were lost at a twoyear follow -up. 
Evidence has shown that online psychological interventions have a similar efficacy in reducing long-term pain compared to face-to-face interventions [28]. Moreover, one of the reported barriers of using psychological interventions for pain is accessibility [29]. Accessibility, alongside cost and geographical location are some of the potential benefits of online psychological interventions [26,30]. One form of delivery of online pain interventions is mobile phone applications whereby an application is downloaded and accessed on a smartphone or tablet device in order for the individual to receive the intervention. In a systematic review, the Headspace ${ }^{\circledR}$ application was found to have the highest average score on the Mobile Application Rating Scale out of all the mindfulness-based phone applications identified in the studies search [15]. The Headspace ${ }^{\circledR}$ application which was developed by trained mindfulness expert Andy Puddicombe, who compiled the sessions, is actively being used by over 2 million users worldwide [19,31]. Although according to the researchers there is little or no published peer-reviewed evidence for mindfulness interventions using mobile phone applications for pain, the Headspace ${ }^{\circledR}$ application is currently being prescribed to both patients and staff as part of a pain intervention in the National Health Service (NHS) in the UK [32]. Huber at al. [33] recently reported on a digital multidisciplinary pain treatment app which includes education, physiotherapy and meditation it reduced userreported pain levels significantly. They evaluated the App in terms of duration of use and effect on user reported pain levels using a rating scale LBP classified into acute or chronic pain.

The primary objective of the study was that the participants would find that carrying out mindfulness training using the Headspace ${ }^{\circledR}$ application would reduce their experience of suffering persistent or intermittent Subacute pain and will perceive the application to be an effective and convenient way to receive mindfulness training.

Further objectives were that there would be (a) an increase in self-reported mindfulness, (b) a negative relationship between pain and self-reported mindfulness, (c) a positive relationship between usage of the application and self-reported mindfulness, (d) a negative relationship between usage of the application and pain,

\section{Methods}

Study Design

Participants’ pain and mindfulness were measured using questionnaires before and after a 6-week mindfulness intervention using the Headspace ${ }^{\circledR}$ application. A duration of 6-weeks was selected because a mindfulness intervention lasting 6-weeks was shown to significantly increase mindfulness in students training to go into helping professions (e.g. nursing, counselling and social work); a similar cohort to the participants in the current study (e.g. physiotherapy, medicine and midwifery ) [34]. At the end of the intervention, open questions were 
completed by the participants and participant adherence to the application was recorded. The study used a quasiexperimental design with no comparison group.

\section{Participants}

Volunteers from a large metropolitan university were recruited to participate in the study. Posters advertising the study were distributed across the university's social media groups. All participants were included if they 1) were a student from the specified university, 2) had pain for a period of six weeks or more, which could be intermittent or persistent in nature (including pain of any cause or location), 3) had daily access to either a smartphone or tablet.

All participants completed and sent back an informed consent form and The Headspace Science Team’s Research Privacy Acknowledgement Form. The lead researcher signed and sent a written consent form to The Headspace Science Team to confirm that all participants had signed the Research Privacy Acknowledgement Form, thereby ensuring anonymity.

\section{Procedure}

All the participants received a letter of invitation and information on the study, mindfulness and the Headspace ${ }^{\circledR}$ application. Following this they were sent their unique code to access the Headspace ${ }^{\circledR}$ application and the baseline questionnaires via email for free.

This application delivers guided and non-guided mindfulness training, with sessions lasting from 10-minutes to 60-minutes [31]. The participants were encouraged to use mindfulness training using the Headspace ${ }^{\circledR}$ application independently for 10-minutes a day for 6 weeks. The App was in English.

After 6-weeks of access to the Headspace ${ }^{\circledR}$ application each participant was sent the follow-up questionnaires to complete and send back via email.

\section{Outcome measures}

Pain was measured using a modified version of The Brief Pain Inventory Questionnaire - 24 hour version Short Form (BPI) before and after the 6-week intervention [35]. This gives a pain severity score which is calculated by adding the scores for questions 2, 3, 4 and 5 and then dividing by 4 . This gives a severity score out of 10. It also gives a Pain Interference Score which is calculated by adding the scores for questions 8a, b, c, d, e, f and g and then dividing by 7. This gives an interference score out of 10.The validity of The Brief Pain Inventory (Short Form) has been demonstrated by Lapane et al.[36] in ambulatory patients in an outpatient setting.

Mindfulness was assessed using The Five Facet Mindfulness Questionnaire (FFMQ) before and after the 6-week 
intervention. A time frame of 6 weeks was considered suitable, as this is in line with traditional face to face and web-based mindfulness interventions [37]. The Five Facet Mindfulness Questionnaire has been validated in both non-meditating and meditating populations [37]. Pain was measured using a modified version of The Brief Pain Inventory Questionnaire - 24 hour version - Short Form (BPI) before and after the 6-week intervention (see Appendix 1). This consists of two components: pain severity and pain interference. It is a selfreported outcome measure which asks participants to rate the severity of their pain on an 11-point Likert scale. A 7-item list forms the pain interference component, which measures the extent to which pain interferes with activities of daily living. Questions also ask participants to provide information on the primary location of pain (indicated on a body chart) and current treatment modalities and medications. An additional question on pain duration was included at baseline but excluded from the scoring. The validity of The Brief Pain Inventory (Short Form) has been demonstrated by Lapane et al. [36] in ambulatory patients in an outpatient setting.

The Five facets of mindfulness include: non-reactivity to inner experience, non-judging of inner experience, acting with awareness, describing and observing. Each of the 39-items are answered on a 5-point Likert scale, which are totalled together for a score which can range from 0 to 195, where greater levels of mindfulness are represented by higher scores.

Individual perceptions of mindfulness using the Headspace ${ }^{\circledR}$ application were analysed using open questions. Usage was measured by calculating the total number of minutes spent on the application for each participant. The Headspace Science Team anonymously received the time data from the phones and sent the break-down of the overall time usage (into days, time of day, length per session, frequency and types of sessions completed) for each code (participant) via email to the researchers to analyze at the end of the intervention.

\section{Data Analysis}

Statistical analysis was carried out using The Statistical Package for Social Sciences (SPSS version 21.0, Armonk, NY, USA). The data was plotted via histograms which identified it to be normally distributed ie the majority of the data was situated between 2 SD above and below the mean. The Wilcoxon Signed Ranks Test was used to analyze pre- to post-intervention changes in BPI and FFMQ scores. The Spearman Rank Correlation Coefficient was used to assess if there was a relationship between (a) mindfulness and self-reported pain, (b) self-reported pain and usage, (c) usage and mindfulness. For all tests the statistical significance ( $\alpha$ ) was set at $p$ $<0.05$ and effect sizes were calculated and interpreted based on Cohen [38].

A Coding Frame was developed according to the frequency analysis as devised by Oppenheim [40] as a way of 
quantifying the qualitative data obtained from the open questions.

\section{Ethics}

Ethical approval was granted by the Faculty of Health and Social Care Sciences Research Ethics Committee before data collection commenced. Procedures were completed according to the accepted ethical application and followed guidance from The Medicines and Healthcare Products Regulatory Agency regarding the use of healthcare applications.

\section{Demographic and clinical characteristics (descriptive data)}

A total of 45 people signed the consent forms, 14 participants did not complete the baseline questionnaires, 2 participants did not download the application and 4 participants did not complete the follow-up questionnaires. 1 participant withdrew from the study before starting the intervention. As such, the data for 24 participants has been reported. From the sample of 24 participants, there was a larger proportion of female (71\%) participants compared to male (29\%). Most participants fell into the age bracket of 18-24 years (71\%), with other responses falling into the 25-35 years (25\%) and 45-54 years (4\%) age brackets. Ethnicity was predominantly White British (42\%), followed by, Black African (20.8\%), other/multiracial (8.33\%), other White (16.7\%), Arab (4.17\%) and Pakistani (4\%). There were no dropouts. The main location of the participants’ pain, their current treatment(s) and duration of pain has been reported in Table 1.

Results

Pre-post changes in pain and mindfulness scores

Box plots have been used to present the findings for pain severity, pain interference and mindfulness, shown in Figures 1 and 2. Pain severity significantly reduced pre- $(M d n=3.5)$ to post-intervention $(M d n=2.1), \mathrm{z}=-3.45$, $\mathrm{p}=0.01, \mathrm{r}=0.70$. Similarly, pain interference significantly reduced from pre- $(\mathrm{Mdn}=2.5)$ to post-intervention $(M d n=1.0), \mathrm{z}=-3.98, \mathrm{p}=0.00, \mathrm{r}=0.81$. Effect sizes were large for pain severity and pain interference [36]. However, there was no significant difference between mindfulness scores from pre- $(M d n=115.5)$ to postintervention $(M d n=117), z=-0.43, p=0.67, r=0.09$.

Usage

The time spent on the application is shown in Figure 3. Time spent on the application ranged from 10 minutes to 674 minutes (mode $=0-100$ ). None of the participants used it less than 10 -minutes a day, each day for the 6week period. However some participants used it more than once on some days which is why two participants achieved over 420 minutes (the number of minutes that would have been completed if the application was used 
for 10-minutes a day over the intervention period) of mindfulness training using the application.

\section{Correlations}

The time spent using the application was not significantly correlated with mindfulness difference scores (twotailed), pre $-r=0.04, p=0.86$, post $-\mathrm{r}=0.11, \mathrm{p}=0.60$. Pain severity (two tailed)- pre $-\mathrm{r}=0.10 \mathrm{p}=0.65$, post $-\mathrm{r}=$ $0.17 \mathrm{p}=0.43$. Pain interference, (two tailed) pre $-r=0.07, p=0.75$ post $\mathrm{r}=0.21 \mathrm{p}=0.32$ Open-ended data

The participants were asked if they perceived the Headspace ${ }^{\circledR}$ application to be beneficial in helping reduce their pain, the results are shown in Table 2. Out of the 24 participants $38 \%$ reported the application was useful in reducing their pain. Others also found it useful but only under certain conditions (4\%) or when pain was less severe (13\%). One participant identified their reduction in pain may have been due to other reasons (4\%). However, $13 \%$ found it was not useful. Two (8\%) participants even reported that they found the application made them more aware of the pain. On the other hand, 33\% reported that it was useful to alleviate other problems, for example, stress or issues with sleeping. In another question the participants were asked if they actively engaged with mindfulness meditation whilst using the application, the results are shown in Table 3. Although $46 \%$ reported they were able to actively engage, $17 \%$ stated that their practice of mindfulness was affected because they were distracted either some of the time (17\%) or most of the time (17\%). However, a couple of participants cited other reasons why they found it challenging to actively engage (8\%) and some reported that they were unable to actively engage (13\%), for example, due to its repetitiveness.

The participants were also asked if they felt the application was the most convenient method in receiving mindfulness training, the results are shown in Table 4. The majority of the participants reported that the application was the most convenient form of providing mindfulness training, either responding with a 'yes' without any explanation (38\%) or providing a positive explanation (25\%), such as accessibility or portability. Although a number of participants found that the application was convenient, they also recognised the benefits of receiving mindfulness training in alternative ways, with groups being cited most commonly (13\%). Whilst 1 participant reported that it was not the most convenient (4\%).

\section{Discussion}

This study aimed to determine the relationship between mindfulness training using the Headspace ${ }^{\circledR}$ application and Persistent or Intermittent Sub-acute Pain. As hypothesized, pain was reduced pre-post intervention. Moreover, large effect sizes were seen for both pain severity and pain interference, supporting previous evidence for the analgesic effect of mindfulness training [41]. There are currently no comparison smartphone- 
based mindfulness interventions to compare the results to, however, significant reductions with moderate to large effect sizes have been seen as a result of other mindfulness-based interventions [42,43, 44, 45]. One of these studies also used the BPI, investigating the benefits of a mindfulness-based program for individuals with chronic pain, showed reductions in pain interference $(\mathrm{p}<0.001)$ and pain severity $(\mathrm{p}<0.04)$ [36]. Moreover, similar results were seen in the current study despite the fact that the duration of pain the participants had experienced prior to commencing the intervention ( $>6$ weeks) was broader than the classification of 'chronic pain' [46]. This suggests that mindfulness training could be of benefit to those with persistent or intermittent sub-acute pain and could be a way that the physiotherapy profession could merge their traditional interventions with a psychological one without sacrificing their professional status [47]. Nevertheless, in the current study, the treatments the participants were receiving were not controlled for nor were they consistently reported throughout the study. Therefore alternative interventions may have contributed or solely been the reason for the reduction in pain. For example, one participant reported in the open questions that although their pain reduced, it may have been due to other reasons. In addition, pain scores were generally on the lower end of the scale at the beginning of the intervention. This is partly reflected by the fact that $33.33 \%$ of the participants were not receiving any treatment (i.e. pain medication) before the intervention commenced. However, it may also be explained by the timeframe on the BPI administered in the current study, which asked participants to report these questions based on their pain in the last 24 hours as this may have not been a long enough time for the participants to have experienced the full extent of their symptoms. Rather the BPI version based on the last 7 days may have been a better outcome measure to reflect a more accurate picture of the participants change in pain over the intervention period, as the inclusion criteria in the current study allowed for individuals with intermittent pain [45].

Despite this, the inclusion of open questions gave an insight into the participants' perceptions of the application in reducing their pain. As such, more than half of the participants reported that mindfulness training using the application reduced their pain at some level. However, the statistical results from the BPI do not explain the proportion of participants who did not find it useful or even had a negative experience. It has been stated that spaced sessions of a short duration of mindfulness training, guided by a trained instructor has minimal risk in causing significant adverse effects [19]. Although no significant adverse effects were seen in this study, two participants reported unpleasant reactions because the application made them more aware of their pain. Unpleasant reactions are not uncommon during mindfulness training and should be taken into consideration 
when prescribing it to patients and staff. In particular because there is limited research on the risks and unpleasant reactions associated with using applications for mindfulness interventions [19].

The open questions therefore provide interesting detail which has not been reported in previous studies and may indicate that mindfulness interventions using the application may not have the same effect in aiming to reduce the perception of pain for all individuals who experience persistent or intermittent sub-acute pain. Therefore, this brings up further interest in understanding the underlying mechanisms of mindfulness, where research is still in its early phases [19].

Mindfulness is considered to be a skill which can be enhanced and deepened through practice [17]. It would then be expected that the completion of mindfulness training will result in an increase in self-reported mindfulness [40]. However, the results of this study showed that there was no significant change. This finding is not an anomaly within the current mindfulness literature and may be explained by the use of the FFMQ as a measure of mindfulness. A systematic review and meta-analysis reported that out of 71 mindfulness-based interventions only 50\% found a significant increase pre-post intervention [43]. A variety of self-reported mindfulness measures were included, including the FFMQ. Nevertheless, when compared, there was no difference in sensitivity to change between the different self-reported mindfulness questionnaires [48]. Moreover, when a mindfulness-based intervention was compared against a validated active control intervention (a target health intervention program), no significant difference between the groups was detected by the FFMQ [49]. This highlights issues surrounding the validity of the self-reported mindfulness questionnaires and poses an issue for researchers aiming to measure changes uniquely related to mindfulness practice received through mindfulness-based interventions [50]. A number of "intractable" issues which limit the current mindfulness scales in capturing this change have been highlighted by authors [50, p1034). One of the main arguments limiting the current mindfulness scales capturing change solely related to mindfulness practice may be the absence of points of reference against which an individual may be defined as mindful. It is therefore difficult to determine exactly what the questionnaires are reflecting, either mindfulness or something else [50].

Additionally, it may be deemed that more exposure to mindfulness practice could lead to changes in how individuals perceive the meaning of self-reported mindfulness [50]. Alternative measurement methods which do not include self-report, such as specific task-related measures or using a second mindfulness teacher for assessments are emerging [51]. However, the lack of time and resources to utilise such methods in the current study meant that it would not have been feasible. 
Frequently studies looking at the effect of mindfulness on pain fail to accurately record and/or report adherence to the intervention [52] . However, this study recorded and reported participant's usage of the application. There was a large variation in total usage between the participants (10-674 minutes). Although the results indicated that usage of the application was generally quite poor, a randomised control trial has shown that even 4 separate days of 20-minute mindfulness sessions can reduce pain after mindfulness training [18]. Nevertheless, pre-post training effects were small in magnitude in comparison to longer mindfulness interventions where moderate to large effect sizes have been reported from 8-week long interventions [52]. However, our results did not follow this trend, as we did not find a negative relationship between usage of the application and pain severity or pain interference. The relationship between usage and pain interference was close to significance in the opposite direction than expected, as a collection of participants whose usage was at the lower end of the spectrum reported greater reductions in pain. One explanation for this is the Hawthorne effect, where behaviour changes occurred with these participants simply because they signed up to a research study and were being observed [53]. The same effect may have not been seen in the self-reported mindfulness scores due to the aforementioned limitations of the FFMQ [50]. Although there is currently limited evidence comparing the duration and frequency of interventions, one author concludes that there is "no one-size-fits-all recommendation" for mindfulness-based interventions, rather the ability to apply the skills learnt through mindfulness training into daily situations is what is vital in order to foster more effective coping methods [19]. It is known that pain can be reduced or changed by refocussing on something else which in this case appears to be the Mindfulness App. However it does appear that the period of usage may not have been long enough to change trait mindfulness as measured by the FFMQ even though it appears to be successful in reducing the pain severity and interference. The variance in usage was very great over the six week period and was not related to the trait mindfulness as measured by the FFMQ, however it may be too linear to suggest that increased use of mindfulness would necessarily result in an increase in trait Mindfulness as this would depend amongst other things on the participants' receptivity. For example, simply repeating a task, in this case listening to the Mindfulness APP several times a day, will not in itself improve trait mindfulness unless it involves attention and motivation by the participant. Equally trait mindfulness as measured by the FFMQ did not correlate with pain severity or pain interference. This could be a lack of sensitivity in the questionnaire but could also be that a level of trait mindfulness could have been reached by the participants that was effective in reducing the severity and interference of their pain experience but is not construed as meaningful by the questionnaire. 
As it has been postulated that smartphone interventions are a convenient form of receiving psychological interventions, one of the open questions was directed at gauging the participant's perceptions of convenience [30] . In line with these beliefs a large proportion of participants did find the application convenient. However, considerations of the drawbacks of using such a platform should be considered. Although some individuals prefer online-individual sessions for reasons such as being able to have control over the time when sessions are completed, others prefer group-based interventions for reasons such as peer support and interaction [28]. Additionally, evidence based on other psychological interventions has shown that the presence of a therapist who can provide feedback either online or face-to-face is beneficial for outcome and adherence [54].

This may make it a good addition to physiotherapy or other approaches dealing with pain interventions. Due to its stipulated neurological effect it may well be suited to a pain education approach. The application did not provide a platform where an instructor can be reached for feedback nor were group-based sessions provided and these drawbacks were recognised by some of the participants in the study. Moreover, in response to another open question nearly half the participants reported that they were able to engage with the application. Although 33.33\% reported some level of difficulty with engagement, this may be explained by the participant's perceptions of mindfulness as a whole rather than the application itself, as evidence has emerged indicating that perceptions of mindfulness influence the levels of engagement [55]. However, one participant cited a specific application-related issue for lack of engagement, stating that it was "repetitive”. Therefore, for these reasons it would be interesting to complete studies comparing the application to the more traditional group-based instructor-led mindfulness interventions.

\section{Limitations}

As previously discussed there were limitations surrounding the chosen self-reported questionnaires [55]. Additionally, there was no active control condition and the sample size was small, affecting the internal validity of the results. Moreover, it could be hypothesised that the sample had positive perceptions of mindfulness as a whole as they entered the study. Engagement and therefore outcome may be different when provided to a patient population where it is prescribed [55] .

Overall pain severity was low at the beginning of the intervention and $12.50 \%$ of participants reported that the application only helped when the pain was less severe, therefore these results may not be applicable for individuals who are experiencing long-term pain which is higher in severity. There was no long-term follow up, therefore it is uncertain if any effects were maintained or if the participants continued to use the application 
following the intervention period. The researchers were also mindful that even if significant correlations were found in some cases this does not infer causation.

\section{Conclusions}

This study provides preliminary evidence to suggest that the Headspace ${ }^{\circledR}$ application is beneficial in reducing Persistent or Intermittent Sub-acute Pain and could be offered by physiotherapists as an adjunct to their treatment. Resources in the NHS are limited and it may not be possible to send patients or staff on costly 8-week long instructor led courses and this study provides initial evidence that the Headspace ${ }^{\circledR}$ application could provide a more accessible alternative. This would allow patients to receive mindfulness training which they are unlikely to receive otherwise. In conclusion further research is merited to investigate the relationship between usage and level of mindfulness and symptoms of pain with a larger sample of people and to include a control group.

\section{Acknowledgements}

The authors would like to say a special thank you to Headspace ${ }^{\circledR}$ for allowing us to use the application and for retrieving and sending the time usage data to us. Also, thank you to those who volunteered to participate in the study.

\section{Conflict of Interest}

The authors declare that they have no conflicts of interest.

\section{References}

[1] Pither CE. Treatment of persistent pain. BMJ: British Medical Journal. 1989; 299(6710):1239.

[2] Alexanders J, Anderson A, Henderson S. Musculoskeletal physiotherapists' use of psychological interventions: a systematic review of therapists' perceptions and practice. Physiotherapy. 2015;101:95-102.

[3] Semmons J. The role of physiotherapy in the management of chronic pain. Anaesthesia \& Intensive Care Medicine. 2016 Sep 1;17:445-7.

[4] Hardison ME, Roll SC. Mindfulness interventions in physical rehabilitation: A scoping review. The American Journal of Occupational Therapy. 2016; 70: 700329003p1-9 
[5] Veehof MM, Trompetter HR, Bohlmeijer ET, et al. Acceptance-and mindfulness-based interventions for the treatment of chronic pain: a meta-analytic review. Cognitive behaviour therapy. 2016; 45(1):5-31.

[6] Björnsdóttir SV, Arnljótsdóttir M, Tómasson G, Triebel J, Valdimarsdóttir UA. Neuroscience patient education and mindfulness added to multidisciplinary rehabilitation for women with chronic musculoskeletal pain. Physiotherapy. 2015;101:e157-8.

[7] Phillips J, Harris P. Helping people to help themselves: an eight-week mindfulness course for people living with a long-term inflammatory condition. Physiotherapy. 2019 Jan 1;105:e151-2.

[8] Majeed MH, Ali AA, Sudak DM. Mindfulness-based interventions for chronic pain: evidence and applications. Asian journal of psychiatry. 2018 Feb 1;32:79-83.

[9] Howells A, Ivtzan I, Eiroa-Orosa FJ. Putting the'app'in happiness: a randomised controlled trial of a smartphone-based mindfulness intervention to enhance wellbeing. Journal of Happiness Studies. 2016; 17(1):163.

[10] Morin CM, LeBlanc M, Daley M, Gregoire JP, Merette C. Epidemiology of insomnia: prevalence, self-help treatments, consultations, and determinants of help-seeking behaviors. Sleep medicine. 2006;7:123-130.

[11] Finan PH, Goodin BR, Smith MT. The association of sleep and pain: an update and a path forward. The Journal of Pain. 2013;14:1539-1552.

[12] Baer RA. Mindfulness training as a clinical intervention: A conceptual and empirical review. Clinical psychology: Science and practice. 2003;10:125-143.

[13] Pickert K. The mindfulness revolution. Time Magazine. 2014;183:184.

[14] Kabat-Zinn J. Mindfulness-based interventions in context: past, present, and future. Clinical psychology: Science and practice. 2003;10:144-156.

[15] Mani M, Kavanagh DJ, Hides L, Stoyanov SR. Review and evaluation of mindfulness-based iPhone apps. JMIR mHealth and uHealth. 2015;3:3.

[16] Cramer H, Haller H, Lauche R, Dobos G. Mindfulness-based stress reduction for low back pain. A systematic review. BMC complementary and alternative medicine. $2012 ; 12: 162$.

[17] Swain NR, Trevena J. A comparison of therapist-present or therapist-free delivery of very brief mindfulness and hypnosis for acute experimental pain. New Zealand Journal of Psychology.

2014;43:22-28.

[18] Zeidan F, Gordon NS, Merchant J, Goolkasian P. The effects of brief mindfulness meditation training on experimentally induced pain. The Journal of Pain. 2010;11:199-209.

[19] Creswell JD. Mindfulness interventions. Annual review of psychology. 2017;68:491-516.

[20] Shapiro SL, Astin JA, Bishop SR, Cordova M. Mindfulness-based stress reduction for health care professionals: results from a randomized trial. International Journal of Stress Management. 2005;12:164.

[21] Flook L, Goldberg SB, Pinger L, Bonus K, Davidson RJ. Mindfulness for teachers: A pilot study to assess effects on stress, burnout, and teaching efficacy. Mind, Brain, and Education. 2013;7:182-195. 
[22] Reiner K, Tibi L, Lipsitz JD. Do Mindfulness-Based Interventions Reduce Pain Intensity? A Critical Review of the Literature. Pain Medicine. 2013;14:230-242.

[23] Lange K, Gorbunova A, Christ O. The influence of mindfulness on different aspects of pain perception and affective reactivity to pain-feasibility of a multimethodical approach. Mindfulness. 2012;3:209-17.

[24] Zeidan F, Grant JA, Brown CA, McHaffie JG, Coghill RC. Mindfulness meditation-related pain relief: evidence for unique brain mechanisms in the regulation of pain. Neuroscience letters. 2012;520:165-173.

[25] Cramer H, Lauche R, Paul A, Dobos G. Mindfulness-based stress reduction for breast cancer-a systematic review and meta-analysis. Current Oncology. 2012;19:e343.

[26] Ludwig DS, Kabat-Zinn J. Mindfulness in medicine. Jama. 2008;300:1350-1352.

[27] Cherkin DC, Anderson ML, Sherman KJ, Balderson BH, Cook AJ, Hansen KE, Turner JA. Two-year follow-up of a randomized clinical trial of mindfulness-based stress reduction vs cognitive behavioral therapy or usual care for chronic low back pain. Jama. 2017 Feb 14;317(6):642-4.

[28] Bender JL, Radhakrishnan A, Diorio C, Englesakis M, Jadad AR. Can pain be managed through the Internet? A systematic review of randomized controlled trials. PAIN ${ }^{\circledR}$. 2011;152:1740-1750.

[29] Sierpina V, Levine R, Astin J, Tan A. Use of mind-body therapies in psychiatry and family medicine faculty and residents: attitudes, barriers, and gender differences. EXPLORE: The Journal of Science and Healing. 2007;3:129-135.

[30] Rini C, Williams DA, Broderick JE, Keefe FJ. Meeting them where they are: Using the Internet to deliver behavioral medicine interventions for pain. Translational behavioral medicine. 2012;2:82-92.

[31] Headspace 2017. https://www.headspace.com/. Accessed June 24, 2017.

[32] Scott, K . NHS England develops national health and wellbeing agenda for 1.3m staff. 2017 https://www.employeebenefits.co.uk/issues/march-online-2017-2/nhs-england-develops-nationalhealth-wellbeing-agenda-1-3m-staff/. Published March 1, 2017. Accessed June 20, 2017.

[33] Huber S, Priebe JA, Baumann KM, Plidschun A, SchiessI C, Tölle TR. Treatment of low back pain with a digital multidisciplinary pain treatment app: short-term results. JMIR rehabilitation and assistive technologies. $2017 \mathrm{Jul} ; 4(2)$.

[34] Newsome S, Waldo M, Gruszka C. Mindfulness group work: Preventing stress and increasing self-compassion among helping professionals in training. The Journal for Specialists in Group Work. 2012;37:297-311.

[35] Daut RL, Cleeland CS, Flanery RC. Development of the Wisconsin Brief Pain Questionnaire to assess pain in cancer and other diseases. Pain. 1983;17:197-210.

[36] Lapane KL, Quilliam BJ, Benson C, Chow W, Kim M. One, two, or three? Constructs of the brief pain inventory among patients with non-cancer pain in the outpatient setting. Journal of pain and symptom management. 2014;47:325-333.

[37] Baer RA, Smith GT, Lykins E, Button D, Krietemeyer J, Sauer S, Walsh E, Duggan D, Williams JM. Construct validity of the five facet mindfulness questionnaire in meditating and non-meditating samples. Assessment. 2008;15:329-342. 
[38] Cohen J. A power primer. Psychological bulletin. 1992;112:155.

[39] Henriksson J, Wasara E, Rönnlund M. Effects of Eight-Week-Web-Based Mindfulness Training on Pain Intensity, Pain Acceptance, and Life Satisfaction in Individuals With Chronic Pain. Psychological reports. 2016; 119(3):586-607.

[40] Oppenheim AN. Questionnaire design, interviewing and attitude measurement. Bloomsbury Publishing; 2000 Oct 17.

[41] Zeidan F, Emerson NM, Farris SR, Ray JN, Jung Y, McHaffie JG, Coghill RC. Mindfulness meditation-based pain relief employs different neural mechanisms than placebo and sham mindfulness meditation-induced analgesia. Journal of Neuroscience. 2015;35:15307-15325.

[42] Morone NE, Greco CM, Moore CG, Rollman BL, Lane B, Morrow LA, Glynn NW, Weiner DK. A mind-body program for older adults with chronic low back pain: a randomized clinical trial. JAMA internal medicine. 2016;176:329-337.

[43] Davis MC, Zautra AJ, Wolf LD, Tennen H, Yeung EW. Mindfulness and cognitive-behavioral interventions for chronic pain: Differential effects on daily pain reactivity and stress reactivity. Journal of consulting and clinical psychology. 2015;83:124.

[44] Cherkin DC, Sherman KJ, Balderson BH, Cook AJ, Anderson ML, Hawkes RJ, Hansen KE, Turner JA. Effect of mindfulness-based stress reduction vs cognitive behavioral therapy or usual care on back pain and functional limitations in adults with chronic low back pain: a randomized clinical trial. Jama. 2016;315:1240-1249.

[45] Garland EL, Manusov EG, Froeliger B, Kelly A, Williams JM, Howard MO. Mindfulness-oriented recovery enhancement for chronic pain and prescription opioid misuse: results from an early-stage randomized controlled trial. Journal of Consulting and Clinical Psychology. 2014;82:448.

[46]Treede RD, Rief W, Barke A, Aziz Q, Bennett MI, Benoliel R, Cohen M, Evers S, Finnerup NB, First MB, Giamberardino MA. A classification of chronic pain for ICD-11. Pain. 2015;156:1003.

[47] Pike AJ. Body-mindfulness in physiotherapy for the management of long-term chronic pain. Physical Therapy reviews 2008; 13: 45-56

[48] Visted E, Vøllestad J, Nielsen MB, Nielsen GH. The impact of group-based mindfulness training on self-reported mindfulness: a systematic review and meta-analysis. Mindfulness. 2015;6:501-522.

[49] MacCoon DG, Imel ZE, Rosenkranz MA, Sheftel JG, Weng HY, Sullivan JC, Bonus KA, Stoney CM, Salomons TV, Davidson RJ, Lutz A. The validation of an active control intervention for Mindfulness Based Stress Reduction (MBSR). Behaviour research and therapy. 2012;50:3-12.

[50] Grossman P. Defining mindfulness by how poorly I think I pay attention during everyday awareness and other intractable problems for psychology's (re) invention of mindfulness: comment on Brown et al.2011.

[51] Levinson DB, Stoll EL, Kindy SD, Merry HL, Davidson RJ. A mind you can count on: validating breath counting as a behavioral measure of mindfulness. Frontiers in psychology. 2014;5.

[52] Goyal M, Singh S, Sibinga EM, Gould NF, Rowland-Seymour A, Sharma R, Berger Z, Sleicher D, Maron DD, Shihab HM, Ranasinghe PD. Meditation programs for psychological stress and well-being: a systematic review and meta-analysis. JAMA internal medicine. 2014;174:357-368. 
[53] Cincotta AL, Gehrman P, Gooneratne NS, Baime MJ. The effects of a mindfulness-based stress reduction programme on pre-sleep cognitive arousal and insomnia symptoms: a pilot study. Stress and Health. $2011 ; 27:$ e299-e305

[54] Andersson G, Cuijpers P, Carlbring P, Riper H, Hedman E. Guided Internet-based vs. face-to-face cognitive behavior therapy for psychiatric and somatic disorders: a systematic review and meta-analysis. World Psychiatry. 2014;13:288-295.

[55] Chadwick P, Newell T, Skinner C. Mindfulness groups in palliative care: a pilot qualitative study. Spirituality and Health International. 2008;9:135-144 [1] Pither CE. Treatment of persistent pain. BMJ: British Medical Journal. 1989; 299(6710):1239. 


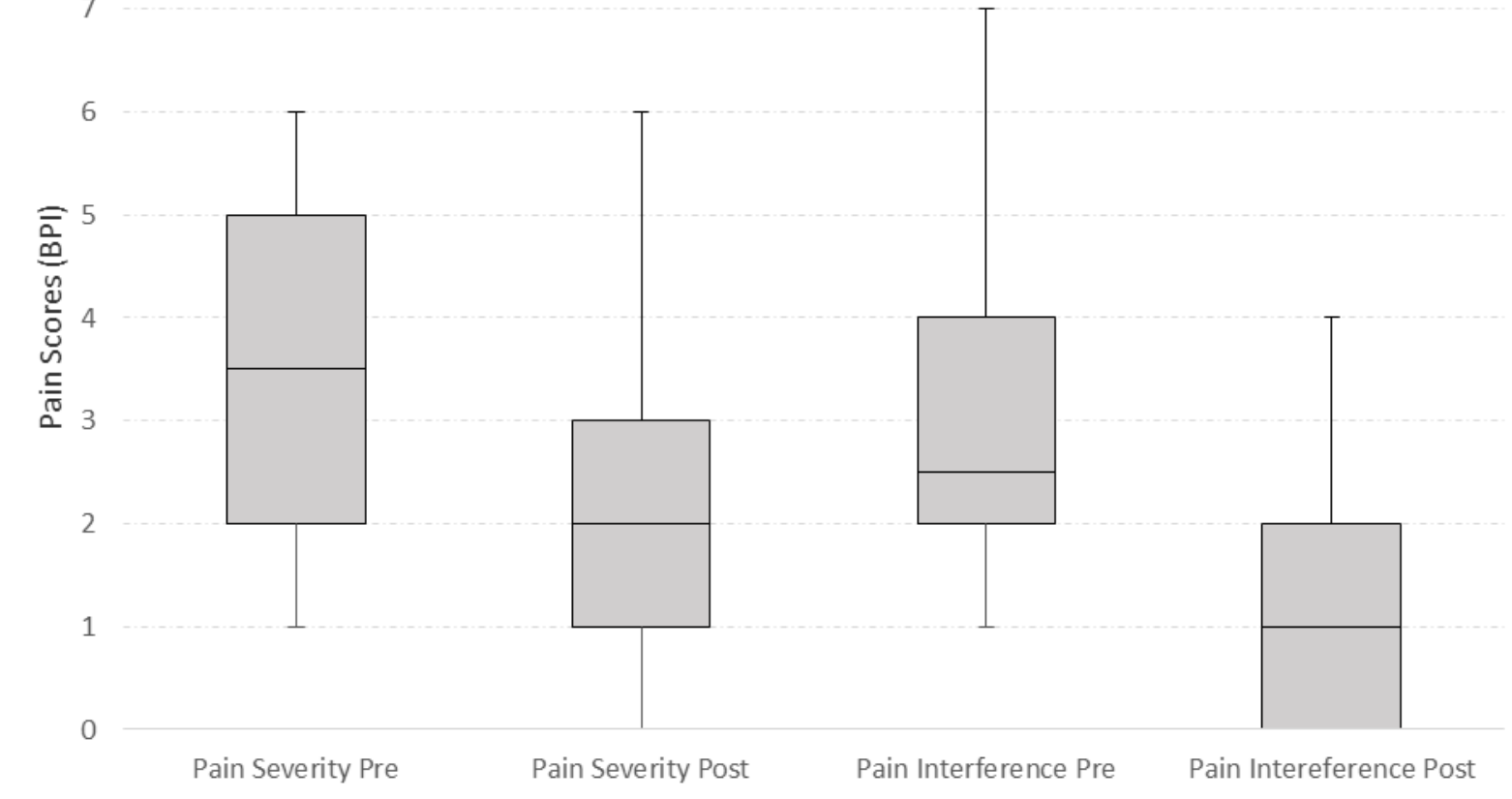

Figure 1. This box plot presents pre- and post- pain severity and pain interference scores. The horizontal line inside the boxes are indicative of the median scores. The $75^{\text {th }}$ percentiles are indicated by the upper hinges and the $25^{\text {th }}$ percentiles are indicated by the lower hinges. The minimum and maximum values and indicated by the lines extending from the boxes.

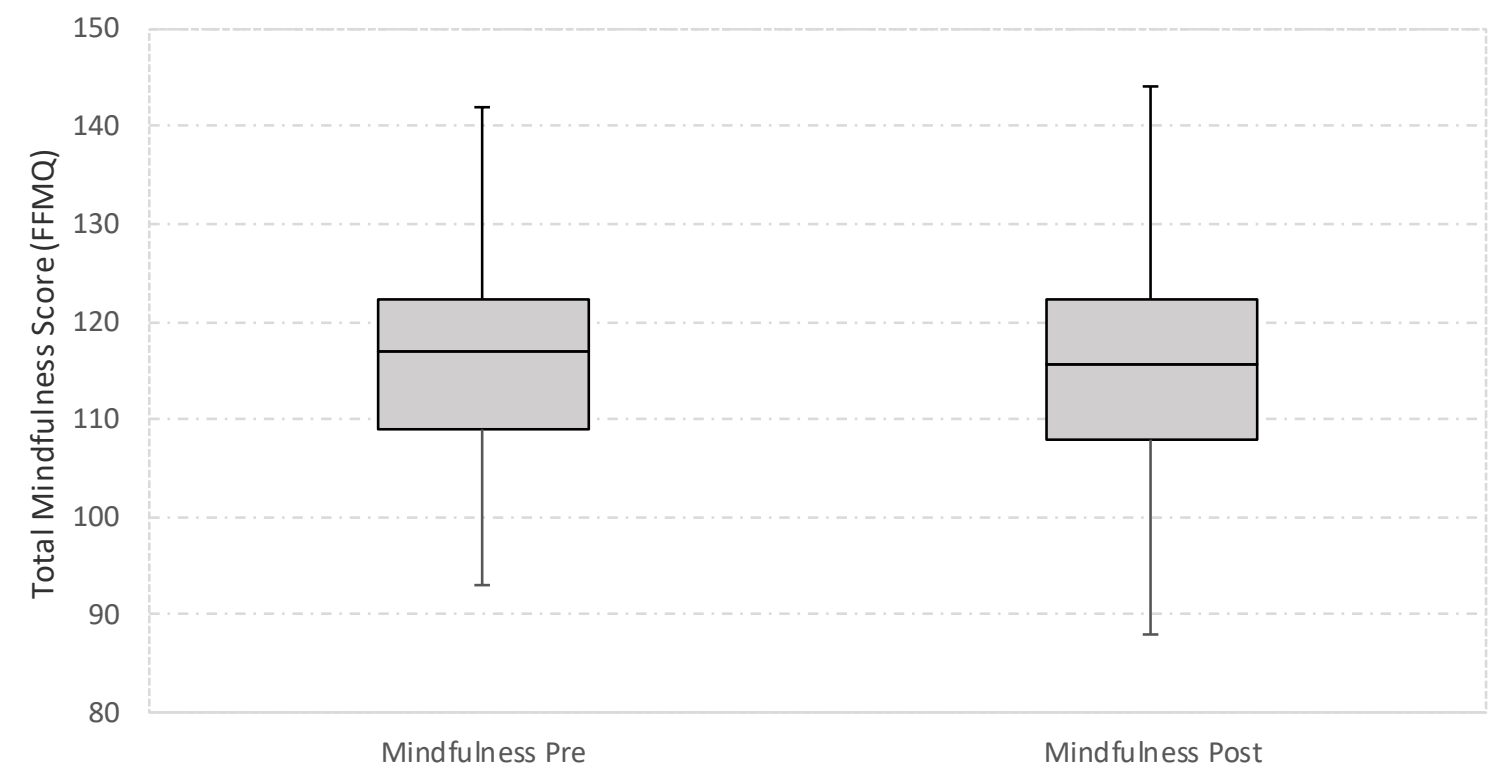

Figure 2. This box plot presents pre- and post- mindfulness scores. The horizontal line inside the boxes are indicative of the median scores. The $75^{\text {th }}$ percentiles are indicated by the upper hinges and the $25^{\text {th }}$ percentiles are indicated by the lower hinges. The minimum and maximum values and indicated by the lines extending from the boxes. 


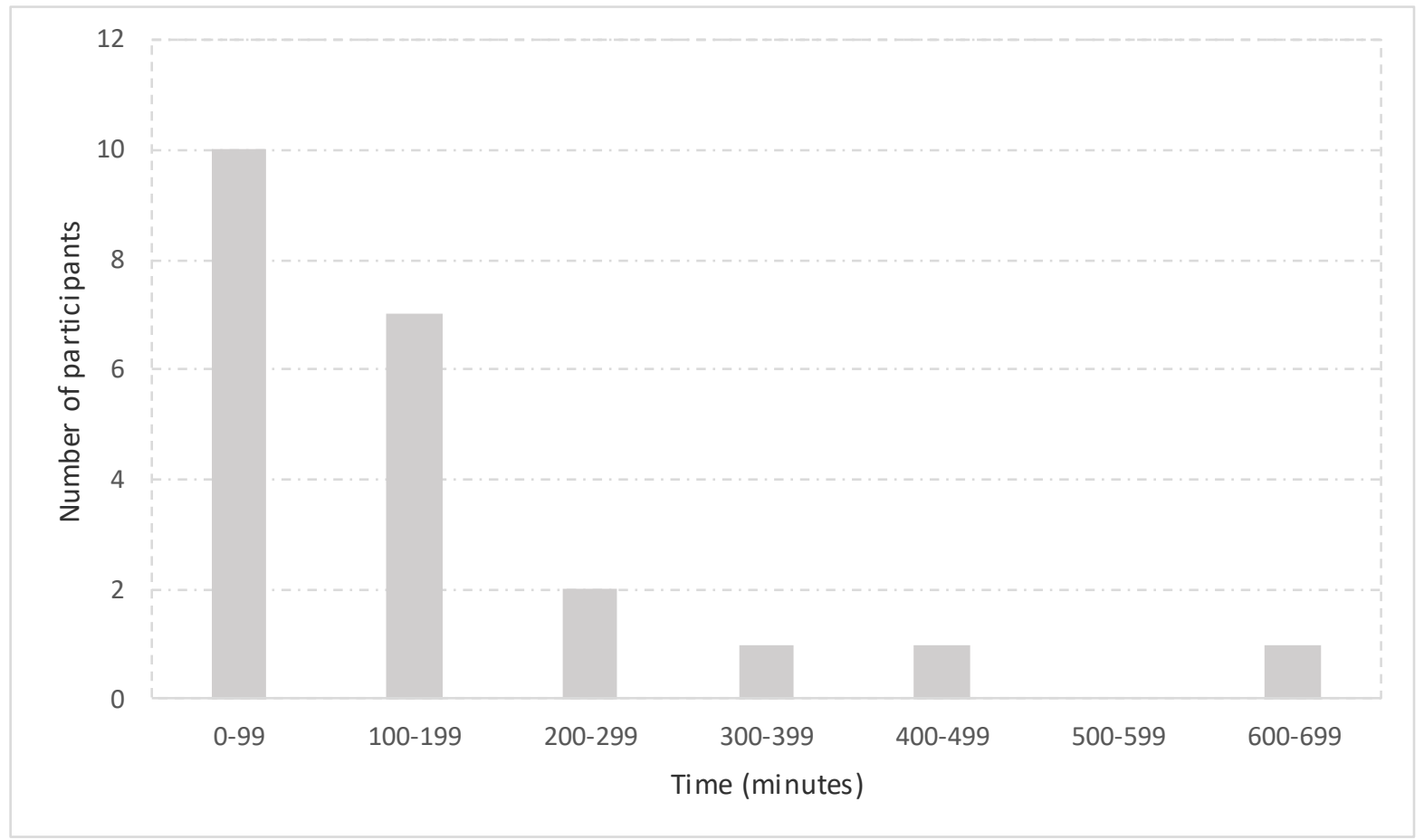

Figure 3. This bar chart presents usage of the Headspace ${ }^{\circledR}$ application as measured in time. The number of participants who fell into each time bracket is shown, with the time bracket indicating the number of minutes spent on the application. 

Table 1. Pain location, current treatment(s) and duration of pain the participants reported at baseline on the BPI $(n=24)$.

\begin{tabular}{|l|l|l|}
\hline \multicolumn{2}{|c|}{ Frequency } & \\
\hline Pain Location & 2 & $8 \%$ \\
Foot & 4 & $17 \%$ \\
Leg & 2 & $8 \%$ \\
Pelvis & 5 & $21 \%$ \\
Lower Back & 1 & $4 \%$ \\
Abdomen & 3 & $13 \%$ \\
Upper Back & 1 & $4 \%$ \\
Chest & 2 & $8 \%$ \\
Shoulder/ Arm & 1 & $4 \%$ \\
Wrist & 3 & $13 \%$ \\
Head & & \\
\hline Current treatment(s) & 12 & $50 \%$ \\
Pain Medication(s) & 2 & $8 \%$ \\
Physiotherapy & 2 & $8 \%$ \\
Physiotherapy and Pain Medication(s) & 8 & $33 \%$ \\
None & & \\
\hline Duration of Pain (Weeks) & 7 & $29 \%$ \\
6-24 & 2 & $8 \%$ \\
25-49 & 3 & $13 \%$ \\
100-149 & 4 & $17 \%$ \\
150-199 & 7 & $29 \%$ \\
$>$ >200 &
\end{tabular}

Table 2. The usefulness of the Headspace ${ }^{\circledR}$ application in reducing pain.

\begin{tabular}{|l|l|l|}
\hline Answer Category & Frequency & Percentage \\
\hline $\begin{array}{l}\text { Not helpful in reducing } \\
\text { pain. }\end{array}$ & 3 & $13 \%$ \\
More aware of pain. & 2 & $38 \%$ \\
$\begin{array}{l}\text { Useful in reducing pain. } \\
\begin{array}{l}\text { Reduction of pain may } \\
\text { be due to other reasons. }\end{array}\end{array}$ & 1 & $4 \%$ \\
$\begin{array}{l}\text { Useful to alleviate other } \\
\text { problems. }\end{array}$ & 8 & $33 \%$ \\
$\begin{array}{l}\text { Useful under certain } \\
\text { conditions. }\end{array}$ & 1 & $13 \%$ \\
$\begin{array}{l}\text { Useful when the pain is } \\
\text { less severe. }\end{array}$ & 3 & $4 \%$ \\
\hline
\end{tabular}


Table 3. Participant self-reported engagement with Headspace ${ }^{\circledR}$ application during mindfulness training.

\begin{tabular}{|l|l|l|}
\hline Answer Category & Frequency & Percentage \\
\hline $\begin{array}{l}\text { Yes - no explanation. } \\
\text { externally distracted. }\end{array}$ & 11 & $46 \%$ \\
$\begin{array}{l}\text { Some of the time but } \\
\text { externally distracted. }\end{array}$ & 4 & $17 \%$ \\
$\begin{array}{l}\text { Other issues (than } \\
\text { distraction) made it more } \\
\text { challenging. }\end{array}$ & 2 & $8 \%$ \\
$\begin{array}{l}\text { No - didn't like the app } \\
\text { or the process } \\
\text { (repetitive). }\end{array}$ & 3 & $13 \%$ \\
Yes - with explanation. & 1 & $4 \%$ \\
\hline
\end{tabular}

Table 4. Convenience of using the Headspace ${ }^{\circledR}$ application for mindfulness training.

\begin{tabular}{|l|l|l|}
\hline Answer Category & Frequency & Percentage \\
\hline Yes - no explanation. & 9 & $38 \%$ \\
$\begin{array}{l}\text { Yes - with positive } \\
\text { explanation. }\end{array}$ & 6 & $13 \%$ \\
$\begin{array}{l}\text { Yes-with drawbacks - } \\
\text { groups better. }\end{array}$ & 3 & $4 \%$ \\
$\begin{array}{l}\text { Yes - with drawbacks - } \\
\text { distracted after time. }\end{array}$ & 1 & $4 \%$ \\
$\begin{array}{l}\text { Yes - with drawbacks - } \\
\text { yoga better. }\end{array}$ & 1 & $8 \%$ \\
$\begin{array}{l}\text { Yes - with drawbacks - } \\
\text { CD better. }\end{array}$ & 1 & $4 \%$ \\
$\begin{array}{l}\text { Yes but no other } \\
\text { experience. }\end{array}$ & 2 & $4 \%$ \\
$\begin{array}{l}\text { No - other methods better } \\
\text { e.g. creative and varied } \\
\text { methods. }\end{array}$ & 1 & $4 \%$ \\
\hline
\end{tabular}

